\title{
HUBUNGAN PENGELOLAAN AIR MINUM DAN MAKANAN RUMAH TANGGA DENGAN KEJADIAN DIARE
}

\author{
Ikrimah, Maharso, Noraida \\ Poltekkes Kemenkes Banjarmasin Jurusan Kesehatan Lingkungan \\ Jl. H. Mistar Cokrokusumo No. 1A Banjarbaru Kalimantan Selatan 70714 \\ Email: ikrimahrima16@gmail.com
}

\begin{abstract}
Relation of Drinking Water Management And Household Food With Diarrhea Occurrence. In Kalimantan Selatan, Kabupaten Hulu Sungai Tengah, Kecamatan Batang Alai Utara, Public Health Center of Ilung is spread of diarrhea. By 2015, the prevalence of diarrhea occurrence in Kecamatan Batang Alai Utara is 2.85\% and 2.7\% (2016). However, the coverage of access to clean water is only about 28\%. Report of KKN Labunganak Village RW. 01 Kecamatan Batang Alai Utara, 67\% is not carried out water purification in any way by the community, so it is still possible to be a media water borne disease. In the management of household food, only $13 \%$ of food is stored in closed shelves / cabinets, so it can become a food borne disease medium.The purpose of this study was to determine the relation between drinking water and household food management with diarrhea occurrence in the working area Public Health Center of Ilung, Kecamatan Batang Alai Utara. The type of research is observational in the form of analytic, research design that is retrospective approach (case control study). The results showed that there was no relation between drinking water management ( $p$ value $=0,300>\alpha=0,05$ ) and household food ( $p$ value $=1,000>\alpha=0,05$ ) with diarrhea occurrence. It is recommended for further investigators to examine other risk factors as causes of diarrhea and can be continued by examining the different communities as control groups .
\end{abstract}

Keywords: Drinking Water and Food Management; Diarrhea Occurrence

Abstrak: Hubungan Pengelolaan Air Minum Dan Makanan Rumah Tangga Dengan Kejadian Diare. Di Kalimantan Selatan Kabupaten Hulu Sungai Tengah Kecamatan Batang Alai Utara, wilayah kerja Puskesmas Ilung tersebar kejadian diare. Pada tahun 2015, prevalensi kejadian diare di Kecamatan Batang Alai Utara mencapai 2,85\% dan 2,7\% (2016). Namun, cakupan akses air bersih hanya sekitar 28\%. Laporan KKN Desa Labunganak RW. 01 Kecamatan Batang Alai Utara, 67\% tidak dilakukan penjernihan air dengan cara apapun oleh masyarakat, sehingga masih memungkinkan menjadi media water borne disease. Pada pengelolaan makanan rumah tangga, hanya $13 \%$ bahan makanan disimpan di dalam rak/lemari tertutup, sehingga dapat memungkinkan menjadi media food borne disease. Tujuan penelitian ini adalah diketahuinya hubungan pengelolaan air minum dan makanan rumah tangga dengan kejadian diare di Wilayah Kerja Puskesmas Ilung Kecamatan Batang Alai Utara. Jenis penelitian adalah observasional dalam bentuk analitik, desain penelitian yaitu pendekatan retrospektif (case control study). Hasil penelitian menunjukkan bahwa tidak ada hubungan pengelolaan air minum ( $p$ value $=0,300>$ nilai $\alpha=0,05)$ dan makanan rumah tangga ( $p$ value $=1,000>$ nilai $\alpha=0,05$ ) dengan kejadian diare. Disarankan bagi peneliti selanjutnya agar meneliti faktor risiko lainnya sebagai penyebab diare dan dapat dilanjutkan dengan meneliti pada komunitas yang berbeda sebagai kelompok kontrol.

Kata kunci; Pengelolaan Air Minum dan Makanan; Kejadian Diare 


\section{PENDAHULUAN}

STBM (Sanitasi Total Berbasis Masyarakat) merupakan program pemerintah dalam rangka memperkuat upaya pembudayaan hidup bersih dan sehat, mencegah penyebaran penyakit berbasis lingkungan, meningkatkan kemampuan masyarakat, serta mengimplementasikan komitmen pemerintah untuk meningkatkan akses air minum dan sanitasi dasar yang berkesinambungan ${ }^{11}$. STBM memiliki 5 pilar, salah satunya yaitu pengelolaan makanan dan minuman rumah tangga.

Pengelolaan air minum dan makanan rumah tangga adalah proses pengolahan, penyimpanan, dan pemanfaatan air minum dan air yang digunakan untuk produksi makanan dan keperluan oral lainnya, serta pengolahan makanan yang aman di rumah tangga, meliputi prinsip hygiene sanitasi pangan, yaitu pemilihan bahan makanan, penyimpanan bahan makanan, pengolahan bahan makanan, penyimpanan makanan, pengangkutan makanan, dan penyajian makanan[2]. Pada pengelolaan makanan rumah tangga, ada batas kemampuan makanan untuk tampil dalam keadaan baik dan sehat, maka perlu dipertimbangkan perencanaan yang matang, pengolahan dan penyajian yang tepat, serta penyimpanan dan penyebaran atau pengangkutan ke tempat lain untuk menekan terjadinya kontaminasi. Penyajian makanan bisa menimbulkan masalah kesehatan bila faktor-faktor hygiene tidak diperhatikan. Hal ini merupakan salah satu faktor yang dapat menyebabkan timbulnya suatu penyakit berbasis lingkungan akibat dari pengelolaan makanan yang tidak tepat ${ }^{[3]}$.

Review dari data Susenas 2013 khusus bidang air minum, tren peningkatan di tahun 2009-2013 mencapai 5\% pertahun. Dalam kurun waktu lima tahun ke depan untuk mencapai universal akses air minum di tahun 2019, diperlukan kenaikan sebesar $5.38 \%$ pertahun[4]. Sebanyak 53,7\% masyarakat yang tidak mempunyai akses terhadap air minum dan rendahnya tingkat pengetahuan masyarakat mengenai air minum yang aman, merupakan faktor penyebab masih tingginya penyakit yang ditularkan oleh air minum[5].

Menurut penelitian Retno Purwaningsih 2014, juga menyebutkan bahwa apabila faktor lingkungan terutama air, tidak memenuhi syarat kesehatan karena tercemar bakteri, didukung oleh perilaku manusia yang tidak sehat seperti pembuangan tinja tidak higienis, kebersihan perorangan dan lingkungan yang jelek, serta penyiapan dan penyimpanan makanan yang tidak semestinya, maka dapat menimbulkan kejadian diare[6].

Penyakit diare masih merupakan masalah kesehatan masyarakat di negara berkembang seperti di Indonesia, karena morbiditas dan mortalitasnya yang masih tinggi[1]. Di Kalimantan Selatan kasus diare masih banyak ditemukan. Pada tahun 2015, kejadian diare yaitu sebanyak 82.010 kasus dan 111.585 kasus (2016)[7]. Kejadian ini tersebar pada 13 kabupaten/kota di Kalimantan Selatan, salah satunya adalah Kabupaten Hulu Sungai Tengah.

Kejadian diare di Kabupaten Hulu Sungai Tengah, pada tahun 2015 yaitu sebanyak 5.403 kasus dan pada tahun 2016 sebanyak 7.506 kasus ${ }^{[8]}$. Angka tersebut tersebar pada 19 kecamatan, salah satunya yaitu Kecamatan Batang Alai Utara. Kecamatan Batang Alai Utara merupakan wilayah kerja Puskesmas Ilung. Pada tahun 2015, prevalensi kejadian diare di Kecamatan Batang Alai Utara mencapai 2,85\% dan 2,7\% (2016) [9]. Namun, cakupan akses air bersih hanya sekitar 28\%[10]. Berdasarkan laporan KKN di Desa Labunganak RW. 01 Kecamatan Batang Alai Utara, sebanyak 67\% masyarakat tidak ada yang melakukan penjernihan air dengan cara apapun, sehingga masih memungkinkan menjadi media water borne disease. Pada pengelolaan makanan rumah tangga, hanya 13\% masyarakat menyimpan bahan makanan di dalam rak/lemari tertutup, sehingga hal ini masih memungkinkan menjadi media food borne disease[11].

Dari uraian tersebut, penulis tertarik untuk melakukan penelitian mengenai hubungan pengelolaan air minum dan makanan rumah tangga dengan kejadian diare di Wilayah Kerja Puskesmas Ilung Kecamatan Batang Alai Utara Kabupaten Hulu Sungai Tengah.

\section{BAHAN DAN CARA PENELITIAN}

Jenis penelitian ini adalah observasional dalam bentuk analitik, yaitu 
untuk mengetahui hubungan pengelolaan air minum dan makanan rumah tangga dengan kejadian diare di Wilayah Kerja Puskesmas Ilung Kecamatan Batang Alai Utara.

Desain penelitian yang digunakan adalah dengan menggunakan pendekatan retrospektif (case control study) yaitu membandingkan antara kelompok kasus dengan kontrol untuk mengetahui proporsi kejadian berdasarkan riwayat ada tidaknya paparan dengan melihat ke belakang dari suatu kejadian yang berhubungan dengan kejadian kesakitan yang diteliti[12].

Populasi dan sampel penelitian ini terdiri dari dua kelompok, yaitu kelompok kasus dan kelompok kontrol. Sampel kasus pada penelitian ini adalah seluruh ibu rumah tangga yang anggota keluarganya pernah menderita diare selama tiga bulan terakhir yaitu pada bulan Desember 2017, Januari dan Februari 2018 dengan jumlah 10 orang responden[13]. Sedangkan sampel kontrol adalah ibu rumah tangga yang anggota keluarganya tidak menderita diare di Wilayah Kerja Puskesmas Ilung, dengan jumlah kontrol sama dengan 3 kali dari jumlah sampel kasus, yang merupakan tetangga dari kasus yaitu sebanyak 30 orang responden. Jadi, total sampel pada penelitian ini yaitu sebanyak 40 orang responden.

Analisis statistik yang digunakan pada penelitian ini yaitu dengan uji chi-square, jika asumsi tidak terpenuhi maka dianalisis dengan uji fisher exact test.

\section{HASIL DAN PEMBAHASAN}

Hasil observasi dan analisis data menggunakan fisher exact test dapat dilihat pada tabel di bawah ini.

Tabel 1. Distribusi Frekuensi Responden Berdasarkan Pengelolaan Air Minum Rumah Tangga di Wilayah Kerja Puskesmas Ilung Tahun 2018

\begin{tabular}{llcc}
\hline No. & Pengelolaan Air Minum Rumah & Frekuensi & \\
Tangga & Jumlah & $\%$ \\
\hline 1. & Buruk & 17 & 42,5 \\
2. & Baik & 23 & 57,5 \\
& Total & 40 & 100 \\
\hline
\end{tabular}

Tabel 1. dapat diketahui bahwa responden pada penelitian ini memiliki

kebiasaan yang buruk dalam pengelolaan air minum yaitu sebanyak 17 orang $(42,5 \%)$.

Tabel 2. Distribusi Frekuensi Responden Berdasarkan Pengelolaan Makanan Rumah Tangga di Wilayah Kerja Puskesmas Ilung Tahun 2018

\begin{tabular}{llccc}
\hline & \multicolumn{2}{c}{ Pengelolaan Makanan Rumah } & Frekuensi \\
No. & & Jumgga & $\%$ \\
\hline 1. & Buruk & & 34 & 85,0 \\
2. & Baik & 6 & 15,0 \\
& Total & 40 & 100 \\
\hline
\end{tabular}

Tabel 2. dapat diketahui bahwa responden pada penelitian ini kebanyakan memiliki kebiasaan buruk dalam pengelolaan makanan rumah tangga yaitu sebanyak 34 orang $(85,0 \%)$. 
Tabel 3. Tabel Silang Hubungan Pengelolaan Air Minum Rumah Tangga dengan Kejadian Diare di Wilayah Kerja Puskesmas Ilung Tahun 2018

\begin{tabular}{llccccc}
\hline \multirow{2}{*}{ No. } & \multicolumn{2}{c}{ Pengelolaan Air Minum Rumah } & \multicolumn{2}{c}{ Kasus } & \multicolumn{2}{c}{ Kontrol } \\
& & Tangga & Jumlah & $\%$ & Jumlah & $\%$ \\
\hline 1. & Buruk & & 6 & 60,0 & 11 & 36,7 \\
2. & Baik & 4 & 40,0 & 19 & 63,3 \\
& Total & 10 & 100 & 30 & 100 \\
& & & \multicolumn{2}{c}{$\alpha=0,05$} \\
\hline
\end{tabular}

Berdasarkan hasil analisis statistik menggunakan uji fisher exact, pada variabel pengelolaan air minum rumah tangga dengan kejadian diare diperoleh nilai $p$ value $=0,300>$ nilai $\alpha=0,05$, maka Ho diterima. Hal ini menunjukkan secara statistik dapat disimpulkan bahwa cukup bukti untuk menyatakan tidak ada hubungan pengelolaan air minum rumah tangga dengan kejadian diare.

Menurut hasil observasi dari pengumpulan data penelitian, diketahui bahwa 10 orang responden dari kelompok kasus kebanyakan memiliki kebiasaan pengelolaan air minum yang buruk sebanyak 6 orang $(60,0 \%)$ dan yang baik sebanyak 4 orang $(40,0 \%)$. Berbeda dari 30 orang kelompok kontrol yang kebanyakan memiliki kebiasaan yang baik dalam pengelolaan air minum rumah tangga yaitu sebanyak 19 orang $(63,3 \%)$ dibandingkan dengan yang memiliki kebiasaan pengelolaan air minum yang buruk sebanyak 11 orang $(36,7 \%)$.

Tidak adanya hubungan dari penelitian ini disebabkan karena pada item pengolahan air minum sebanyak 97,5\% responden melakukan perebusan air sampai mendidih dan pada item wadah penyimpanan air minum sebanyak $40 \%$ responden memenuhi penilaian wadah penyimpanan yang bersih, tertutup, sulit dijangkau vektor dan dilakukan pencucian pada wadah air minum ketika air habis. Walaupun sebagian responden tidak memenuhi pada item penyimpanan wadah makanan, tetapi mereka melakukan perebusan air sehingga dapat mengurangi risiko penyakit diare.

Teori dari Kepmenkes (2008) yang menyebutkan bahwa kejadian diare dapat menurun 39\% dengan perilaku pengelolaan air minum yang aman di rumah tangga. Teori dari Wanzahun G et al (2013) menyebutkan bahwa anak dengan keluarga yang menggunakan air minum dengan cara direbus, diolah menggunakan bahan kimia atau diolah dengan cara penyaringan diketahui memiliki peluang lebih rendah menderita diare dibanding dengan anak yang keluarganya tidak melakukan pengolahan air[14].

Akan tetapi secara statistik tidak ada hubungan, karena responden yang pengelolaan air minumnya baik belum tentu tidak menderita diare dan responden yang pengelolaannya buruk juga belum tentu menderita diare, hal ini juga dapat dilihat dari tabel 3 bahwa pada kelompok kasus sebanyak $60 \%$ responden melakukan pengelolaan air minum yang buruk sedangkan pada kelompok kontrol sebanyak $63,3 \%$ melakukan pengelolaan air minum yang baik, sehingga hampir tidak jauh berbeda persentasi responden yang pengelolaan air minumnya baik dengan yang buruk, serta penyakit diare juga dapat diakibatkan oleh faktor lain seperti perilaku CTPS, BAB, pengelolaan sampah ataupun limbah cair rumah tangga.

Tabel 4. Tabel Silang Hubungan Pengelolaan Makanan Rumah Tangga dengan Kejadian Diare di Wilayah Kerja Puskesmas Ilung Tahun 2018

\begin{tabular}{llccccc}
\hline & \multirow{2}{*}{ No. } & \multicolumn{2}{c}{ Pengelolan Makanan Rumah } & \multicolumn{2}{c}{ Kasus } & \multicolumn{2}{c}{ Kontrol } \\
& & Tangga & Jumlah & $\%$ & Jumlah & $\%$ \\
\hline 1. & Buruk & & 8 & 80,0 & 26 & 86,7 \\
2. & Baik & Total & 2 & 20,0 & 4 & 13,3 \\
& & $p$ value $=1,000$ & 10 & 100 & 30 & 100 \\
& & \multicolumn{2}{c}{$\alpha=0,05$} \\
\hline
\end{tabular}


Berdasarkan hasil analisis statistik menggunakan uji fisher exact, pada variabel pengelolaan makanan rumah tangga dengan kejadian diare diperoleh nilai $p$ value $=1,000>$ nilai $\alpha=0,05$, maka Ho diterima. Hal ini menunjukkan secara statistik untuk menyatakan cukup bukti bahwa tidak ada hubungan pengelolaan makanan rumah tangga dengan kejadian diare.

Hasil observasi data penelitian, diketahui bahwa dari 10 orang responden pada kelompok kasus dan 30 orang responden dari kelompok kontrol cenderung memiliki kebiasaan pengelolaan makanan rumah tangga yang buruk yaitu sebanyak 8 orang $(80,0 \%)$ dari kelompok kasus dan 26 orang $(86,7 \%)$ dari kelompok kontrol. Sedangkan pengelolaan makanan rumah tangga yang baik hanya 2 orang responden $(20,0 \%)$ dari kelompok kasus dan 4 orang responden $(13,3 \%)$ dari kelompok kontrol. Hal ini menunjukkan bahwa pengelolaan makanan rumah tangga antara kelompok kasus dan kelompok kontrol hampir tidak ada beda, keduanya kebanyakan melakukan pengelolaan makanan rumah tangga yang buruk. Ini disebabkan karena sebanyak 32 responden $(80,0 \%)$ tidak memenuhi penilaian pengolahan makanan.

Berdasarkan analisis statistik di atas, tidak adanya hubungan antara pengelolaan makanan dengan kejadian diare dapat dikarenakan penyakit diare merupakan salah satu penyakit yang penyebabnya multifaktor. Diantaranya dapat disebabkan karena perilaku BAB, CTPS, pengelolaan sampah dan pengelolaan limbah cair rumah tangga.

Menurut Depkes RI 2014 dalam Mila Falasifa 2015, makanan harus dikelola dengan baik dan benar agar tidak menyebabkan gangguan kesehatan dan bermanfaat bagi tubuh. Cara pengelolaan makanan yang baik yaitu dengan menerapkan prinsip higiene dan sanitasi makanan. Pengelolaan makanan di rumah tangga, walaupun dalam jumlah kecil atau skala rumah tangga juga harus menerapkan prinsip higiene sanitasi makanan yaitu meliputi pemilihan bahan makanan, penyimpanan bahan makanan, pengolahan makanan, penyimpanan makanan matang, pengangkutan makanan, dan penyajian makanan[14].

\section{KESIMPULAN DAN SARAN}

Berdasarkan hasil penelitian dan analisis data yang telah dilakukan maka dapat disimpulkan bahwa pengelolaan air minum rumah tangga sebagian besar adalah baik yaitu sebanyak 23 orang responden $(57,5 \%)$, pengelolaan makanan rumah tangga sebagian besar adalah buruk yaitu sebanyak 34 orang responden $(85,0 \%)$, kejadian diare yaitu sebanyak 10 orang $(25,0 \%)$, tidak ada hubungan pengelolaan air minum rumah tangga dengan kejadian diare, dan tidak ada hubungan pengelolaan makanan rumah tangga dengan kejadian diare di Wilayah Kerja Puskesmas Ilung Kecamatan Batang Alai Utara.

Disarankan untuk peneliti lain agar meneliti faktor risiko lainnya sebagai penyebab diare karena penyakit diare merupakan penyakit yang multifaktor sehingga kejadian diare ini kemungkinan disebabkan oleh faktor lain yang lebih dominan misalnya perilaku CTPS, penggunaan jamban, pengelolaan sampah dan limbah rumah tangga (tidak diteliti) dan diharapkan dapat melanjutkan penelitian dengan cara meneliti pada komunitas yang berbeda sebagai kelompok kontrol. Tidak terbukti adanya hubungan antara pengelolaan makanan rumah tangga terhadap kejadian diare kemungkinan disebabkan karena kontrol dicuplik dari tetangga kasus sehingga sangat mungkin menjadi sama (match), serta dilakukan perbaikan pengelolaan makanan rumah tangga pada daerah studi meskipun secara statistik tidak terbukti merupakan faktor risiko diare, akan tetapi kasus diare masih ada sehinggga kasus diare diharapkan dapat lebih ditekan.

\section{KEPUSTAKAAN}

1. Dinar Andaru Mukti, Mursid Raharjo, dan Nikie Astorina Yunita Dewanti. 2016. Hubungan Antara Penerapan Program Sanitasi Total Berbasis Masyarakat (STBM) dengan Kejadian 
Diare di Wilayah Kerja Puskesmas Jatibogor Kabupaten Tegal. Jurnal Kesehatan Masyarakat Volume 4, Nomor 3, Juli 2016 (ISSN: 2356-3346)

2. Depkes RI. 2015. Kurikulum dan Modul Pelatihan Untuk Pelatih (TOT) Fasilitator STBM.

3. Hartono, H. 1991. Penyehatan Jasa Boga, Kumpulan Makalah Pelatihan Hygiene Sanitasi Makanan dan Minuman Bagi Guru APK/SPPH se Indonesia. Yogyakarta.

4. Kemenkes RI. 2014. Kurikulum dan Modul Pelatihan Wirausaha Sanitasi Total Berbasis Masyarakat (STBM). Jakarta

5. Athena dan Indah. 2012. Implementasi Pengelolaan Air Minum Rumah Tangga (PAM-RT) di Jawa Barat Dan (Nusa Tenggara Timur). Jurnal Ekologi Kesehatan Vol. 11 No 2, Juni 2012: 136-146

6. Retno Purwaningsih. 2012. Hubungan Antara Penyediaan Air Minum dan Perilaku Higiene Sanitasi Dengan Kejadian Diare di Daerah Paska Bencana Desa Banyudono Kecamatan Dukun Kabupaten Magelang. Universitas Negeri Semarang. Skripsi.

7. Direktorat Jenderal P2P, Kemenkes RI. 2016. Data dan Informasi Profil
Kesehatan Indonesia 2016. http://www.depkes.go.id/resources/ download/pusdatin/lain-lain/Data dan Informasi Kesehatan

8. Dinas Kesehatan Hulu Sungai Tengah. 2015-2016. Profil Kesehatan Kabupaten Hulu Sungai Tengah.

9. Data Puskesmas Ilung Kecamatan Batang Alai Utara Tahun 2015-2016 tentang Data Angka Kejadian Diare

10. Data Puskesmas Ilung Kecamatan Batang Alai Utara Tahun 2015-2016 tentang Data Cakupan Akses Air Bersih.

11. Laporan KKN Poltekkes Kemenkes Banjarmasin Jurusan Kesehatan Lingkungan Tahun 2017.

12. Notoatmodjo, S. 2012. Metodologi Penelitian Kesehatan. Jakarta : PT Rineka Cipta. Cetakan Kedua

13. Data Puskesmas Ilung Kecamatan Batang Alai Utara Tahun 2018 tentang Data Kejadian Diare.

14. Mila Falasifa. 2015. Hubungan Antara Sanitasi Total Dengan Kejadian Diare Pada Balita di Wilayah Kerja Puskesmas Kepil 2 Kecamatan Kepil Kabupaten Wonosobo. Universitas Negeri Semarang. Skripsi 